\title{
LA PROTECCIÓN DE LAS SUPERVIVIENTES DE TRATA DE PERSONAS CON FINES DE EXPLOTACIÓN SEXUAL: NORMATIVA Y REALIDADES
}

\author{
Autoras: Elena Laporta Hernández \\ laportaelena@gmail.com \\ Universidad Carlos III de Madrid \\ Samara de las Heras Aguilera \\ samara.delasheras@gmail.com \\ Asesora Jurídica de la Asociación Trabe y Universidad Carlos III de Madrid
}

\begin{abstract}
Resumen
La trata de personas con fines de explotación sexual representa una de las mayores amenazas al respeto, protección y garantía de los derechos humanos, dado el elevado número de personas afectadas y la magnitud de las violencias y discriminaciones que conlleva. Es incuestionable que su erradicación exige incorporar de manera plena un enfoque de derechos humanos interseccional y una perspectiva feminista, y que su reconocimiento normativo y aplicación práctica son todavía insuficientes. Con este artículo, las autoras pretenden contribuir al debate sobre la
\end{abstract}


protección de las víctimas, a partir de su experiencia tanto académica como práctica en el acompañamiento a mujeres supervivientes, apelando al potencial transformador del Derecho y a una concepción holística y multidisciplinar de la Justicia.

Palabras Clave: Trata de personas; explotación sexual; Feminismo; derechos humanos; interseccionalidad; acceso a la Justicia.

The protection of survivors of human trafficking for the purpose of sexual exploitation: regulation and realities

\begin{abstract}
Human trafficking for the purpose of sexual exploitation poses one of the greatest threats to the respect, protection and fulfillment of human rights, given the large number of persons harmed, and the scale of violences and discriminations involved. It is unquestionable that its eradication requires a full integration of a human rights and intersectional approach and a feminist perspective, and that its legal recognition and practical implementation are still not enough. The authors of this paper intend to contribute to the debate on the protection of victims based on both their academic and practical experience accompanying survivors, advocating for the transformative strength of Law and a holistic and multidisciplinary notion of Justice.
\end{abstract}

Key words: Trafficking in persons; sexual exploitation; Feminism; human rights; intersectionality; access to Justice.

Fecha de recepción: 09/02/2019

Fecha de aceptación: 21/06/2019

\title{
I. LA TRATA DE PERSONAS DESDE UN CONOCIMIENTO SITUADO: TEORÍA Y PRÁCTICA
}

La trata de personas con fines de explotación sexual representa, hoy en día, una de las formas de violencia contra las mujeres más grave, por su prevalencia a nivel mundial si atendemos al número de víctimas y por las vulneraciones de derechos que conlleva. Si bien es cierto que existen otras formas de trata de seres humanos, y que algunas de ellas tienen también un claro impacto de género, 
como aquella con fines de explotación laboral en el sector doméstico y de cuidados o los matrimonios forzados, en el presente artículo nos centraremos en la que se produce con fines de explotación sexual por una razón básica: es con diferencia la modalidad más frecuente en España y en Europa ${ }^{1}$.

Según la información aportada en 2017 por el Gobierno de España al GRE$\mathrm{TA}^{2}$, el grupo de personas expertas en la materia del Consejo de Europa, España es fundamentalmente un país de destino, y también de tránsito hacia otros estados europeos, de víctimas de trata de personas con fines de explotación sexual y, en menor medida, con fines de explotación laboral.

En otras palabras, la mayoría de víctimas de trata de personas en España, como en Europa, son mujeres, mayoritariamente migrantes, que ven mermado, cuando no impedido, el disfrute de los derechos más básicos (UNODC, 2010, pp. 44 y 14). Considerando lo anterior, y que el Derecho es una herramienta que puede coadyuvar a promover cambios sociales y combatir (o mantener) los sistemas de dominación (Facio \& Fries, 1999, p. 56) que posibilitan la trata de personas, cabe indagar en la respuesta institucional para frenar la trata de personas y evitar que aumenten las víctimas, por un lado, y para proteger, atender, reparar los derechos vulnerados y facilitar que las supervivientes puedan continuar con sus vidas libres de violencia, discriminación y explotación, por otro lado.

\section{APUNTES SOBRE LA REGULACIÓN DE LA TRATA DE PERSONAS: AVANCES E INCOHERENCIAS}

Precisamente por lo anterior, en las últimas dos décadas se ha venido aprobando un conjunto de normas y políticas públicas dirigidas a luchar contra la esclavitud moderna, tanto en el plano internacional y europeo, como en España en particular. Si bien es cierto que desde principios del siglo XX la adopción de varios tratados internacionales refleja la preocupación de la comunidad internacional por un delito que a menudo tiene un componente transnacional, podríamos considerar que es a partir de la adopción del Protocolo para prevenir, reprimir y sancionar la trata de personas, especialmente mujeres y niños (en adelante, "Protocolo

1 En ese sentido, la Oficina de las Naciones Unidas contra la Droga y el delito (2018, p. 10) señala que "los pocos estudios nacionales que se han llevado a cabo en países europeos para determinar el número total de víctimas y sus perfiles han mostrado que la trata con fines de explotación sexual es la forma más prevalente de trata”. La traducción es de las autoras.

2 El Grupo de Expertos sobre la lucha contra la trata de seres humanos (conocido como "GRETA", por sus siglas en inglés) es el organismo encargado de velar por que los Estados parte apliquen el Convenio del Consejo de Europa sobre la lucha contra la trata de seres humanos. El llamado Convenio de Varsovia, fue aprobado en 2005 y ratificado en 2009 por España, que ha sido evaluada en dos ocasiones por el GRETA: en 2013 y en 2018. Información disponible en: https://www.coe.int/en/web/anti-human-trafficking/spain 
de Palermo"), cuando se establecen los lineamientos comunes que sustentan las vigentes normativas y políticas públicas contra la trata de seres humanos.

De hecho, el Protocolo de Palermo acuerda por primera vez una definición consensuada, en el marco de la Organización de las Naciones Unidas (en adelante, "ONU"). Precisa que por trata de personas se entiende "la captación, el transporte, el traslado, la acogida o la recepción de personas, recurriendo a la amenaza o al uso de la fuerza u otras formas de coacción, al rapto, al fraude, al engaño, al abuso de poder o de una situación de vulnerabilidad o a la concesión o recepción de pagos o beneficios para obtener el consentimiento de una persona que tenga autoridad sobre otra, con fines de explotación" (artículo 3.a). Entre esas formas de explotación, menciona expresamente la explotación de la prostitución ajena u otras formas de explotación sexual, sin aportar una descripción de las mismas, debido a la falta de consensos en el debate más amplio sobre cómo regular la prostitución (Chuang, 2013, pp. 176-177).

Al margen de lo farragoso de la definición ${ }^{3}$, que por su redacción parece dar más importancia a las acciones y a los medios comisivos y, por tanto, a la falta de consentimiento de la víctima, que al hecho de la explotación y las vulneraciones de derechos que supone, se ha considerado que un acuerdo internacional en esta materia implica una lucha más efectiva contra la trata de personas.

Por un lado, porque los tratados internacionales firmados anteriormente en esta materia adolecían de un planteamiento sesgado, que a menudo omitía algunas formas de explotación e invisibilizaba a multitud de víctimas. Es más, los primeros acuerdos a nivel internacional en la materia se centraban en la (incorrectamente) denominada "trata de blancas"4 y se limitaban a enfrentar la explotación sexual.

\footnotetext{
${ }^{3}$ Asimismo, y sin pretender abrir un debate sobre esta cuestión, consideramos que la expresión trata de personas no es la más adecuada para dar cuenta de las vulneraciones de derechos y de la violencia que entraña la explotación de una persona. En ese sentido, cabe recordar que el lenguaje es relevante porque incide en el imaginario colectivo, en este caso invisibilizando las explotaciones y violencias que conlleva la esclavitud moderna, según la terminología utilizada, entre otros, por el Tribunal Europeo de los Derechos Humanos.

${ }^{4}$ El término "trata de blancas" se recoge desde el Acuerdo Internacional para Asegurar una Protección Eficaz contra el Tráfico Criminal Denominado Trata de Blancas, adoptado en París en 1904, con la finalidad de evitar que ciudadanas de los Estados parte fueran trasladadas "con el fin de darlas a la vida depravada en el extranjero" (artículo 1). En cuanto a las mujeres extranjeras que eran explotadas en el ámbito de la prostitución, sólo se preveía su repatriación, una vez establecida su identidad, su estado civil "e investigar quién las hizo tomar la determinación de dejar su país" (artículo 3). Posteriormente, se ha utilizado la misma expresión en el Convenio Internacional para la Represión de la Trata de Blancas (1910), y, aunque se menciona en el Convenio Internacional para la Represión de la Trata de Mujeres y Niños (1921), ya entonces se propuso su sustitución por "trata de mujeres y niños", término que se mantiene en la Convención internacional para la represión de la trata de mujeres mayores de edad (1933). Es posible argumentar que el concepto trata de blancas es inadecuado, por el racismo que emana y, por tanto, por la discriminación que conlleva, y porque no representa la realidad de la mayoría de las víctimas de trata de personas en la actualidad, que son a menudo mujeres, niñas, niños y hombres migrantes y racializadas/os. En consecuencia,
} 
En ese sentido, es preciso apuntar la importancia de reconocer todas las formas de explotación, entre ellas, "la explotación de la prostitución ajena u otras formas de explotación sexual, los trabajos o servicios forzados, la esclavitud o las prácticas análogas a la esclavitud, la servidumbre o la extracción de órganos”, advirtiendo en línea con el Protocolo de Palermo (artículo 3), que no deben plantearse como un listado cerrado y estanco. No podemos olvidar la necesidad de nombrar y regular todos aquellos actos (y omisiones) que entrañan vulneraciones de derechos, para poder actuar y proteger a las víctimas. Tampoco podemos obviar que en ocasiones las víctimas son explotadas con distintas finalidades, y pueden ser sometidas a explotación sexual al tiempo que son obligadas a cometer actos delictivos como hurtos, o bien ser re-tratadas una vez pagada la deuda inicial, para ser explotadas en el sector doméstico y de cuidados, por mencionar dos ejemplos.

Por otro lado, es fundamental partir de definiciones consensuadas en el plano internacional por los Estados, teniendo presente que la Oficina de las Naciones Unidas contra la Droga y el Delito (en adelante, "UNODC") apunta que frecuentemente los/as tratantes operan en redes transnacionales. Ello exige una respuesta que desborda el ámbito de la Justicia a nivel estatal y debería sustentarse en la cooperación internacional (UNODC, 2018, p. 13).

Cabe recordar al respecto que la diversidad de normas entre Estados y, en especial la distinta manera de tipificar este delito en los Códigos Penales, dificulta una lucha coordinada y común frente a las redes internacionales de delincuencia. En consecuencia, el Protocolo de Palermo (artículo 2.c), como otras normas posteriores que se han adoptado a nivel supraestatal, tienen entre sus fines últimos la mejora de la coordinación y la cooperación entre Estados.

Además de dicho consenso en la definición de la trata de personas, el Protocolo de Palermo marca un hito por el modo de abordar la trata de personas. Destaca que se propone a los Estados adoptar una actuación integral, que permita prevenir el delito, perseguir y sancionar a las personas responsables del mismo y proteger adecuadamente a las víctimas (artículo 2). La exigencia de esa triple actuación, propia de la normativa sobre derechos humanos, ha sido replicada por las normas más relevantes en esta materia a nivel europeo, el Convenio del Consejo de Europa sobre la lucha contra la trata de seres humanos, adoptado en Varsovia en 2005 (en adelante, "Convenio de Varsovia"), y la Directiva 2011/36/UE del Parlamento Europeo y del Consejo, de 5 de abril de 2011, relativa a la prevención y lucha contra la trata de seres humanos y a la protección de las víctimas (en adelante, "Directiva 2011/36/UE”).

desde la Declaración Universal de los Derechos Humanos, adoptada en 1948 en el marco de la actual Organización de las Naciones Unidas, la práctica totalidad de las normas hacen referencia a "trata de personas" o "trata de seres humanos", como podemos observar en el título del Convenio para la represión de la trata de personas y de la explotación de la prostitución ajena (1949) o en el Protocolo de Palermo (2000). 
Sin embargo, dicha propuesta se ve afectada por el enfoque que subyace en las medidas concretas para luchar contra la trata de seres humanos. Es decir, las respuestas institucionales varían en función del contexto político, económico y social, las concepciones teóricas asumidas para explicar sus causas, los derechos e intereses que se consideran vulnerados y los imaginarios sobre las víctimas y victimarios (Cortés, Becerra, López \& Quintero, 2011, p. 106).

Una de las aproximaciones más frecuente es la criminal, que sitúa el foco en la persecución del delito y la sanción de los/as tratantes. De hecho, el propio Protocolo de Palermo integra un tratado más amplio, la denominada Convención contra la delincuencia organizada transnacional, lo que explica que la trata de personas se plantee en términos propios del Derecho Penal, y que su ámbito de aplicación se refiera a "la prevención, investigación y penalización de los delitos tipificados" con arreglo al articulado (artículo 4).

Sin desconocer la importancia de actuar desde el ámbito policial y penal para evitar la impunidad, máxime teniendo constancia de las bajísimas tasas de identificación de las víctimas y del escaso número de condenas (UNODC, 2018, p. 13), consideramos que este enfoque debe ser complementado con otras visiones que garanticen una protección y atención integral y reparadora a las víctimas, atendiendo a sus circunstancias y necesidades concretas.

Por consiguiente, desde distintas instancias (y en la práctica totalidad de las normas) se exige actuar desde un enfoque de derechos, que propugna que toda actuación de los poderes públicos debe tener como fin último la protección de las víctimas en su sentido más amplio, garantizando la no repetición del delito, evitando la revictimización y brindando una atención integral que permita reparar los daños sufridos y restablecer todos los derechos conculcados (Cortés et. al., 2011, p. 109). Sin embargo, los datos de los que disponemos muestran que, a pesar del reconocimiento formal de la necesidad de actuar desde un enfoque de derechos, es frecuente que en la práctica las víctimas no accedan a la protección, bien porque los poderes públicos no actúan con la diligencia debida, bien porque se supedita a su colaboración con las Fuerzas y Cuerpos de Seguridad y el Poder Judicial asumiendo un enfoque puramente criminal, bien porque se priorizan otras cuestiones, como puede ser la seguridad de las fronteras y el orden público 5 .

De hecho, es frecuente que la trata de personas (o algunos aspectos de la misma) se regule en normas que pretenden el control de las migraciones y que parecen ignorar que, como señala de Janie Chuang (1998, p. 68), este tipo de delitos se alimentan de la pobreza, el sexismo y el racismo, que se interrelacionan para

${ }^{5}$ En otras palabras, "con mucha frecuencia la identificación de las víctimas se hace post hoc y está relacionada demasiado estrechamente con la necesidad de establecer la identidad de las víctimas para los procesos penales o migratorios, y no como medida preventiva para evitar las situaciones de explotación que pueden aumentar la susceptibilidad a la trata” (Relatora, 2015: párrafo 24). 
crear situaciones desiguales de poder y vulnerabilidad, que se acrecientan cuando las víctimas se hallan en situación administrativa irregular, como observamos las profesionales que acompañamos a las víctimas en sus procesos de recuperación.

Por último, es posible hacer referencia a un cuarto enfoque desde el que abordar la trata de personas: el feminista, que es el que consideramos más acertado para garantizar los derechos de las personas supervivientes, especialmente cuando son mujeres y niñas, aunque no exclusivamente. En otras palabras, se propone asumir la denominada perspectiva de género ${ }^{6}$ por las normas que articulan la respuesta política y jurídica frente a la trata de personas, que implica tener presente cómo y por qué este delito afecta de distintas maneras a mujeres y a hombres, y considerar esas diferencias a la hora de adoptar medidas de prevención del delito y de investigación, persecución y sanción de las personas responsables del mismo y, fundamentalmente, en las actuaciones dirigidas a las supervivientes en materia de protección, atención y reparación. Es más, en palabras de la Relatora Especial sobre la violencia contra la mujer, con inclusión de sus causas y consecuencias, en su informe (2000, párrafo 80 ) sobre la trata de mujeres, la migración de mujeres y la violencia contra la mujer, "todos los remedios o estrategias propuestos para combatir la trata y prestar asistencia a sus víctimas deben evaluarse determinando si y cómo promueven y protegen los derechos humanos de las mujeres".

\section{EL FEMINISMO COMO ESTRATEGIA DE CAMBIO: MIRANDO A LAS SUPERVIVIENTES}

No podemos olvidar que el Feminismo surge, como los derechos humanos, vinculado a la Ilustración, con el fin de desvelar la exclusión de las mujeres de la ciudadanía, los espacios públicos y los procesos de toma de decisiones, así como las contradicciones del sistema jurídico-político y de las prácticas sociales dominantes (de las Heras, 2009, pp. 47-48). Desde esa primera ola de activismo y argumentación, se han planteado análisis y propuestas que, sin duda, coadyuvan a evidenciar las causas que subyacen en la trata de personas con fines de explotación sexual, así como a mejorar el proceso que permite dar cumplimiento a las obligaciones derivadas del marco jurídico de protección de los derechos de las víctimas.

\footnotetext{
${ }^{6}$ La perspectiva de género es una herramienta desarrollada a raíz de aportaciones del movimiento feminista, fundamentalmente en la década de los noventa. Ha sido incorporada a la normativa relativa a los derechos humanos, desde que en la IV Conferencia Mundial sobre la Mujer, celebrada en Pekín en 1995, se acordó que el "éxito de las políticas y de las medidas destinadas a respaldar o reforzar la promoción de la igualdad de género y la mejora de la condición de la mujer debe basarse en la integración de una perspectiva de género" ( $\$ 57)$, recomendando a los Estados "promover una política activa y visible encaminada a incorporar una perspectiva de género en todas las políticas y los programas de manera que, antes de que se adopten decisiones, se analicen los efectos que han de tener para las mujeres y los hombres" (\$229).
} 
Especialmente útiles a tal fin encontramos los postulados, metodologías y propuestas realizadas desde el Feminismo Jurídico ${ }^{7}$ que, tanto desde la teoría como desde la práctica del Derecho, busca avanzar hacia sociedades más justas e igualitarias (Facio \& Fries, 1999, p. 25), en las que la violencia y la discriminación contra las mujeres por el hecho de serlo no tengan cabida.

Más aún, teniendo presente que la trata de personas con fines de explotación sexual representa una forma de violencia contra las mujeres que se sustenta en la ideología patriarcal, puesto que como ha afirmado Catharine MacKinnon (1995, pp. 218 y 436), "la objetificación sexual es el proceso primario de sometimiento de las mujeres".

Así se reconoce en las normas que especifican los derechos humanos desde la aprobación en 1979 de la que podríamos considerar la carta fundacional de los derechos de las mujeres en el plano internacional, la Convención para la eliminación de todas las formas de discriminación contra la mujer (en adelante, "CEDAW", por sus siglas en inglés), que exige que los Estados adopten todas las medidas necesarias para erradicar todas las formas de trata de mujeres y, en particular, la "explotación de la prostitución". Asimismo, debemos mencionar la Declaración sobre la eliminación de la violencia contra la mujer, adoptada en 1993, que incluye "la trata de mujeres y la prostitución forzada" como manifestaciones de la "violencia continua y endémica" que las mujeres sufrimos por el hecho de ser mujeres (preámbulo y artículos 1 y 2.b).

Asumiendo este enfoque, el punto de partida, compartido en buena parte de los análisis feministas ${ }^{9}$, es el proceso de toma de conciencia sobre las necesidades y realidades específicas de las mujeres, diversas de las de los hombres, tomando como referencia las experiencias personales y el debate sobre las vivencias compartidas, tanto por las personas supervivientes como por las profesionales que las acompañan en sus procesos de recuperación (Bartlett, 1990, p. 866).

7 Aunque los análisis del Derecho han sido una constante desde el origen del movimiento feminista, el Feminismo Jurídico encuentra su máximo desarrollo en las Facultades de Derecho de países anglosajones y escandinavos en la década de los sesenta del pasado siglo XX (Bartlett \& Kennedy, 1991, p. 1). Aunando teorías (y prácticas) críticas del Derecho, se propone analizar el Derecho desde una perspectiva de género con el fin de conocer y eliminar las desigualdades y discriminaciones promovidas por los sistemas jurídicos (Barnett,1998, p. 4), aportando una pluralidad de métodos de análisis y actuación, a menudo innovadores y con potencial transformador, como por ejemplo se ha reflejado en la regulación de la violencia contra las mujeres.

${ }^{8}$ El artículo 6 de la CEDAW establece que los estados parte de la Convención, como es el caso de España que la ratificó en 1984, "tomarán todas las medidas apropiadas, incluso de carácter legislativo, para suprimir todas las formas de trata de mujeres y explotación de la prostitución contra la mujer".

${ }^{9}$ En palabras de Catharine MacKinnon (1982, p. 519), el aumento de conciencia «es la más importante técnica de análisis, estructura de organización, método de práctica, la teoría del cambio social del movimiento de mujeres». 
En consonancia con lo anterior, consideramos relevante destacar que las autoras del presente artículo comparten tanto su compromiso en la defensa de los derechos de las mujeres a través de la concienciación y su interés como investigadoras en los análisis del Derecho desde un enfoque feminista, como su experiencia profesional como asesoras jurídicas en centros de atención a víctimas de violencia contra las mujeres y, específicamente, de trata con fines de explotación sexual ${ }^{10}$. De los debates generados en diversos espacios de reflexión entre juristas y profesionales de otras disciplinas ${ }^{11}$ y de las voces de las supervivientes a las que hemos acompañado para facilitar el ejercicio de los derechos que les son inherentes, como personas, ciudadanas y víctimas, se nutren buena parte de las reflexiones planteadas en este artículo.

Asumiendo que ese conocimiento situado no nos permite entender como universales las vivencias de grupos particulares de mujeres (Bartlett, 1990, p. 866), es suficiente para afirmar que las experiencias y necesidades de las supervivientes son diversas, puesto que el proceso de recuperación del hecho de haber sido (o estar siendo) víctima de trata de personas con fines de explotación sexual, se ve condicionado por las circunstancias personales, familiares, sociales e incluso por las redes de apoyo, entre ellas las públicas. De ahí la necesidad de incorporar la interseccionalidad como método de análisis que permite, como apunta Catharine MacKinnon (2013, p. 1019), tener presentes las múltiples realidades, desigualdades, discriminaciones y violencias que enfrentan las supervivientes y la interacción entre las mismas, con el fin de ofrecer una respuesta que considere en toda su complejidad su momento vital y sus necesidades concretas.

Sin obviar las responsabilidades que como profesionales del ámbito jurídico tenemos, es fundamental recordar que corresponde a los poderes públicos la obligación última de proteger a las víctimas, garantizarles el ejercicio de todos los derechos y atender sus necesidades hasta su plena recuperación. Es preciso cuestionarse, por tanto, en qué medida las normas y políticas públicas adoptadas en España son efectivas a tales efectos y adecuadas a los estándares de derechos humanos promovidos por las normas internacionales y europeas.

10 Elena Laporta Hernández ha trabajado como abogada y asesora jurídica en casos de violencia contra las mujeres. Samara de las Heras Aguilera trabaja desde principios de 2017 en el Centro municipal Concepción Arenal, de atención integral especializada a mujeres en situación de prostitución y/o víctimas de trata con fines de explotación sexual, del Ayuntamiento de Madrid y gestionado por la Asociación Trabe.

11 Entre ellos, en los foros de reflexión habilitados en el marco del Curso online La trata de personas: una visión jurídico-política, coordinado anualmente desde el año 2012 en la plataforma de formación de Feminicidio.net por las dos autoras, y en los talleres organizados por el Grupo de Estudios Feministas de la UC3M, del que ambas forman parte. Página web disponible en: http://portal.uc3m.es/portal/page/portal/ instituto_derechos_humanos/investigacion/grupo-estudios-genero- 
Con ese objetivo, en las páginas que siguen analizamos desde un enfoque feminista o de género la situación de las víctimas de trata de personas con fines de explotación sexual, tomando en consideración las medidas contenidas en las normas y políticas públicas vigentes en España, así como la actuación de las diversas instituciones que crean, aplican o tutelan dichas normas.

\section{LA TRATA DE SERES HUMANOS CON FINES DE EXPLOTACIÓN SEXUAL EN ESPAÑA: VÍNCULOS ENTRE HECHOS Y DERECHOS}

Advirtiendo que los datos recogidos por los poderes públicos son insuficientes y sesgados, éstos muestran que la trata de personas en España alcanza una magnitud intolerable es un Estado Social y Democrático de Derecho, por el número de víctimas afectadas, y por las gravísimas vulneraciones de derechos que padecen.

Según el Centro de Inteligencia contra el Terrorismo y el Crimen Organizado (en adelante, "CITCO"), se calcula que en la actualidad hay algo más de 10.000 personas en situación de riesgo de estar siendo víctimas de trata con fines de explotación sexual en España ${ }^{12}$. La cifra ascendía a 13.159 en 2013; 13.983 en 2014; 13.879 en 2015; 12.419 en 2016; y 10.111 en 2017, por lo que cabe apreciar un ligero descenso sostenido en los datos en los últimos años, que podría deberse bien al descenso del número de víctimas, en contra de las tendencias a nivel global (UNODC, 2018, p. 13), bien a su traslado a lugares de ejercicio de prostitución más invisibles o menos accesibles que las calles, como pisos y clubes. En consecuencia, se han llevado a cabo más de 2.000 inspecciones por año en lugares de ejercicio de prostitución entre el 2013 y el $2017^{13}$ pero, a pesar de lo anterior, destaca el reducido número de mujeres identificadas formalmente como víctimas, competencia que en España corresponde a las Fuerzas y Cuerpos de Seguridad del Estado.

En otras palabras, cuando se contabiliza el que se considera por el Estado español el número total de víctimas identificadas como tales, la cifra se reduce considerablemente, siendo muy superior en el caso de las mujeres y niñas que en el de

\footnotetext{
12 A ellas hay que sumar las posibles víctimas de trata con fines de explotación laboral y aquellos casos en los que se tiene indicios de que son explotadas con otras finalidades, de las que no se tienen datos. En el caso de la primera, se han detectado 10.835 en 2015, 11.427 en 2016 y 12.807 en 2017, considerando que el número total de víctimas formalmente identificadas se reduce a 134 en 2015, 25 en 2016 y 58 en 2017 (CITCO, 2018). Respecto a otros tipos de trata el número de personas consideradas víctimas se reduce drásticamente: en el caso del matrimonio forzado, 4 en 2016 y 3 en 2017; en el de la criminalidad forzada 15 en 2016 y 1 en 2017; en el de mendicidad, 1 en 2016 y 3 en 2017.

${ }^{13}$ En concreto, las inspecciones realizadas fueron 2.555 en 2013; 2.962 en 2014; 3.007 en 2015; 2.586 en 2016 y 2.228 en 2017 (CITCO, 2018).
} 
hombres y niños. En el año 2017 ascienden a 124 mujeres víctimas (251 en 2013; 142 en 2014; 126 en 2015; y 138 en 2016) y 22 hombres, cifra ésta última que se ha incrementado considerablemente con respecto a las de años anteriores (1 en 2013; 4 en 2014; 4 en 2015; 4 en 2016). Además, se registran 9 casos de niñas en 2017 (12 en 2013; 4 en 2014; 3 en 2015; 4 en 2016) pero ninguno de niños, lo que viene siendo habitual en los últimos años (3 en 2014, y ninguno en 2013 ni en el periodo 2015-2017, según datos del CITCO (2018).

Distintos son los datos que manejan las organizaciones no gubernamentales (en adelante, "ONGs") y entidades especializadas en trata de mujeres con fines de explotación sexual. A modo de ejemplo, el informe del GRETA señala que según fuentes gubernamentales, las ONGs contactaron en 2016 con 52.872 mujeres en situación de prostitución, detectando señales de trata de personas en 16.387 casos (la mitad procedentes de Nigeria y Rumanía) y de explotación sexual en 3.858 (GRETA, 2018, p. 36).

Las víctimas que contactan o son detectadas ${ }^{14}$ por las entidades sociales de intervención y/o las ONGs, y que no desean comunicar a la policía su situación, no quedan recogidas en las estadísticas oficiales, cuestión ésta que ha llevado al GRETA a recomendar al Estado español que las incluyan en las cifras y que establezcan un sistema estadístico integral, que reúna tanto los datos sobre investigaciones, enjuiciamientos y condenas, como los relativos a las medidas de protección y promoción de sus derechos (GRETA, 2018, p. 18).

Desde el punto de vista judicial, la Fiscalía incoa 107 diligencias de seguimiento por delito de trata de seres humanos con fines de explotación sexual durante el año 2017, si bien, como indica, ello no significa que éstas concluyan con una sentencia condenatoria, apuntando que un número considerable de las incoadas hasta el 2016 han sido archivadas en el 2017 (Fiscalía, 2018, p. 1). En sentido similar, el Consejo General del Poder Judicial (en adelante, "CGPJ”) (2017) en una investigación sobre la trata de personas ha señalado:

(...) una gran parte de los procedimientos incoados van a ser archivados por varios motivos, significativamente por carecer de relevancia penal la conducta perseguida

14 En España, se distingue entre la identificación formal de las víctimas de trata de personas, que realiza la Policía o la Guardia Civil (y en particular, la UCRIF y la UCO, también responsables de la lucha contra el crimen organizado y el control de las fronteras, cuestión que supone un impedimento para que muchas de las víctimas tomen la decisión de denunciar), y la detección por parte de las ONGs y entidades sociales de intervención. Sólo la identificación formal permite el acceso a ciertos derechos previstos por el ordenamiento jurídico español, como por ejemplo, el permiso de residencia por la situación personal de la víctima, en caso de que se halle en situación administrativa irregular. En consecuencia, el GRETA (2018, p. 13) ha recomendado a España que mejore los protocolos de detección e identificación de las víctimas, que debe realizarse en colaboración con las entidades y organizaciones de la sociedad civil y otros agentes sociales. 
(proxenetismo consentido) o no llegar a acreditarse los elementos abusivos. Es relativamente sencillo llevar adelante una acusación cuando se prueba la utilización de violencia o intimidación para determinar o mantener la prostitución de la víctima adulta o en todo caso de corrupción de menores. Es prácticamente imposible obtener una sentencia condenatoria cuando el medio comisivo consiste en el abuso de una situación de superioridad, necesidad o vulnerabilidad de la víctima mayor de edad. Muchas otras, son un duplicado de las que ya se encuentran registradas como supuestos de trata de seres humanos o de tráfico ilegal de inmigrantes con fines de explotación sexual o difícilmente van a desembocar en una sentencia condenatoria.

De hecho, el número de condenas es ínfimo, comparado con el número de posibles víctimas. Según el Instituto Nacional de Estadística (2018) fueron 63 en 2017; 123 en 2016; 103 en 2015; 30 en 2014; 39 en 2013. De acuerdo a la información facilitada al GRETA, específicamente las condenas con privación de libertad han sido de 5 en 2013; 8 en 2014, aunque una de ellas finalmente fue considerada abuso sexual por el Tribunal Supremo; 18 en 2015; y 16 en 2016.

Según la Fiscalía, las víctimas provienen de cuatro continentes: África, donde todas las víctimas son mujeres (132 nigerianas; 1 de Guinea Conakry y 1 de Guinea Ecuatorial); América, con 4 hombres víctimas (1 hondureño y 3 venezolanos, y otros 24 ciudadanos sudamericanos de distintas nacionalidades víctimas potenciales) y 81 mujeres ( 5 brasileñas; 24 colombianas, 1 cubana, 3 hondureñas, 39 paraguayas, 3 dominicanas y 5 venezolanas); Asia, con 15 mujeres víctimas originarias de China; y Europa, donde son todas mujeres ( 4 albanesas, 27 búlgaras, 9 españolas, 1 húngara, 1 italiana, 51 rumanas, 3 rusas y 2 ucranianas y 63 mujeres en riesgo respecto de las cuales no se conoce su nacionalidad). Este órgano las describe como mujeres "extranjeras, pobres y extraordinariamente vulnerables" (Fiscalía, 2018, pp. 4-5).

Respecto de las víctimas, señala por su parte el CGPJ (2018) en su informe que "en casi todas las calificaciones se relatan hechos de extraordinaria gravedad por la violencia ejercida sobre las víctimas, el sometimiento a constantes amenazas y las gravosas condiciones de vida a la que están sometidas".

Teniendo en cuenta esos datos, son evidentes varias cuestiones: la primera, que el enfoque de género e interseccional es prioritario, dado el sexo y la procedencia de las víctimas, mayoritariamente mujeres migrantes; la segunda, que existe una desmesurada diferencia entre quienes son consideradas personas en situación de riesgo y las que finalmente son reputadas como víctimas: ¿Qué ocurre, entonces, con las primeras? ¿Qué tipo de asistencia y protección reciben?; en tercer lugar, no existe un informe estatal anual (ni de ningún otro tipo) que aglutine el conjunto de la información estadística, por lo que es necesario acudir a fuentes heterogéneas las cuales, a su vez, utilizan mecanismos diversos para recopilar unos datos que, además, son manifiestamente insuficientes, lo que dificulta el análisis de la 
situación y el diseño e implementación de políticas públicas efectivas. Huelga recordar que, como ha señalado la Relatora Especial sobre la trata de personas (en adelante la "Relatora"), contar con datos empíricos exactos es parte de la diligencia debida en esta materia ${ }^{15}$.

A pesar de lo anterior, de lo que no cabe duda es de que, siendo la trata de seres humanos una vulneración grave de diversos derechos humanos ${ }^{16}$, el elevado número de casos en España requiere, de manera urgente, un abordaje integral. Es cierto que el Estado español ha firmado y ratificado los instrumentos internacionales y regionales más importantes relacionados con ésta ${ }^{17}$, así como también los referentes a la violencia por razón de sexo y/o género contra las mujeres ${ }^{18}$.

No existe, sin embargo, una ley integral ${ }^{19}$, de tal manera que su regulación en el ámbito estatal está fragmentada en dos tipos de normas: aquellas que son vinculantes pero no se refieren específicamente a la trata de personas, salvo referencias puntuales $^{20}$; y aquellas otras que sí se dirigen concretamente a ésta, pero no son de obligado cumplimiento ${ }^{21}$.

Todo ello sin olvidar que además hay otro grupo de normas que perjudican claramente a las víctimas, colocándolas en una situación de mayor vulnerabilidad: es el caso de la Ley Orgánica 4/2015, de 30 de marzo de Protección de la Seguridad Ciudadana y de ciertas ordenanzas municipales que penalizan la prostitución y que tienen como efecto la invisibilización de mujeres víctimas de trata de seres humanos, que son obligadas a prostituirse en espacios cerrados para evitar las sanciones y por ende dificultan, cuando no impiden, que se tomen medidas para protegerlas

15 Informe de María Grazia Giammarinaro, Relatora Especial sobre la trata de personas, especialmente mujeres y niños, párrafo 21, UN Doc. A/70/260 (2015).

16 Así ha quedado reconocido, entre otros, por el Tribunal Europeo de Derechos Humanos: STEDH (Sección 1aㅡ). Asunto Rantsev contra Chipre y Rusia, demanda 25965/04, 7 de enero de 2010; (Sección $1^{a}$ ). Asunto L.E. contra Grecia, demanda 71545/12, 21 de enero de 2016; (Sección 1ª $)$. Asunto S.M. contra Croacia, demanda 60561/14 de 19 de julio de 2018.

17 Aunque se ha mantenido por diversas organizaciones que dicha Directiva no se ha traspuesto íntegramente, al limitarse a incorporar las pertinentes reformas al Código Penal.

18 De las múltiples denominaciones que existen para nombrar esta violación de los derechos de las mujeres, las autoras han partido de la utilizada por el Comité CEDAW en su Recomendación General número 35 sobre la violencia por razón de género contra la mujer, por la que se actualiza la Recomendación General número 19, UN Doc. CEDAW/C/GC/35, 2017.

19 Ésta es una reclamación que las ONGs llevan planteando desde hace varios años y que no se ha empezado a valorar por el Estado español hasta el año pasado, en el marco del Pacto de Estado contra la Violencia de Género.

20 Por ejemplo, la Ley 4/2015, de 27 de abril, del Estatuto de la víctima del delito menciona únicamente en dos ocasiones a las víctimas de trata de personas. Esta ley se aplica principalmente en aquellos casos en los que se han iniciado procesos penales, y adolece de una falta de recursos importantes para desplegarse en toda su integridad, como lo demuestra el hecho de que no se hayan puesto en funcionamiento todas las Oficinas de Atención a las víctimas previstas.

${ }^{21}$ Ministerio de Sanidad, Servicios Sociales e Igualdad, Plan integral de lucha contra la trata de mujeres y niñas con fines de explotación sexual 2015-2018. 
y atenderlas. En ese sentido, debemos recordar que las víctimas no deben ser enjuiciadas ni sancionadas por su participación en actividades ilícitas que se hayan visto obligadas a cometer (artículo 8 de la Directiva 2011/36/UE). Sin embargo, el GRETA (2018:55) afirma tener constancia de sanciones en virtud de dicha ley a víctimas de trata de personas, que para pagar la multa a menudo tienen que aumentar las horas que dedican al ejercicio de la prostitución.

En definitiva, son muchos los obstáculos que enfrentan las víctimas de trata de personas, la mayoría derivados de su situación de explotación y, otros tantos, de los estereotipos y discriminaciones que enfrentan en su día a día como consecuencia de la falta de concienciación social e institucional.

Preocupa especialmente que todavía no se reconozca legalmente como una forma de violencia contra las mujeres por razón de género ${ }^{22}$ en el ámbito estatal ${ }^{23}$, lo que implica que no se está cumpliendo con las obligaciones internacionales que España tiene en la materia. De ahí la importancia de que el Pacto de Estado en materia de Violencia de Género ${ }^{24}$ haya incluido un eje dirigido a la visibilización y atención de otras formas de violencia contra las mujeres, incluida a la trata de personas con fines de explotación sexual.

Este Pacto resulta además de interés porque, en particular respecto a la trata de personas, propone algunas medidas que ponen de manifiesto ciertas trabas, que, como se verá a continuación, están relacionadas con la necesaria profundización en un enfoque integral, de derechos humanos, de género e interseccional. Entre ellas, se propone aprobar una ley orgánica integral y multidisciplinar contra la trata de seres humanos con fines de explotación sexual, con especial énfasis en la creación de mecanismos y servicios adecuados para la prevención, protección y recuperación de las víctimas (medida 259) ${ }^{25}$. Dicha ley entrañaría la reforma

22 Recordamos que en el ámbito estatal, la Ley Orgánica 1/2004, de 28 de diciembre, de Medidas de Protección Integral contra la Violencia de Género tiene un objeto limitado a la violencia que sufren las mujeres por sus parejas y ex parejas y, aunque el Plan integral de lucha contra la trata de mujeres y niñas con fines de explotación sexual 2015-2018, se refiere a ésta como una forma de violencia por razón de género, no es ésta una norma vinculante ni cuenta con un mecanismo de evaluación externa.

${ }^{23}$ En algunas legislaciones autonómicas, las leyes que abordan la violencia por razón de género contra las mujeres, incluyen la trata de personas como una forma más de violencia machista. Esto supone que no existe en ese sentido una homogeneización infraestatal.

${ }^{24}$ Este Pacto tiene su origen en la aprobación en el Pleno del Congreso de los Diputados el 15 de noviembre de 2016, de una Proposición no de Ley por la que se instó al Gobierno a promover la suscripción de un Pacto de Estado por el Gobierno de la Nación, las Comunidades Autónomas y Ciudades con Estatuto de Autonomía y la Federación Española de Municipios y Provincias. Esa Proposición se plantea como resultado de la presión de las organizaciones especializadas, académicas y activistas comprometidas con la lucha contra la violencia machista. El Pacto está disponible en el siguiente enlace: http://www.violenciagenero.igualdad.mpr.gob.es/pactoEstado/docs/Documento_refundido_PEVG_.pdf

${ }_{25}$ Documento refundido por la Delegación del Gobierno para la Violencia de Género, de las medidas del Pacto de Estado en materia de Violencia de Género. 
legislativa de varias leyes, en particular la llamada "Ley de Extranjería"26 para eludir los procedimientos sancionadores por estancia irregular (medida 98) o la "Ley de Testigos"27, para mejorar la protección de víctimas, testigos y denunciantes (medida 261). Asimismo, se pretende reducir la victimización secundaria adaptando determinadas dependencias de los Juzgados de Violencia sobre la Mujer y juzgados especializados, permitiendo que éstas se utilicen también en los casos de trata de personas con fines de explotación sexual (medida 133). Por último, sería necesario establecer indicadores objetivamente verificables para determinar el grado de cumplimiento del enfoque integral de derechos humanos que contempla el Plan Integral en las fases de seguimiento (medida 260).

Todo ello porque hoy en día ya es incuestionable que la trata de personas con fines de explotación sexual exige un abordaje integral, desde la perspectiva de derechos humanos, género e interseccionalidad, en la medida en que constituye una violación grave de derechos humanos, tiene un impacto claramente diferenciado sobre las mujeres y afecta principalmente a aquellas que sufren diversas formas de discriminación (por ejemplo, por el hecho de ser personas migradas y encontrarse en una situación económica y social de enorme precariedad). Son muchos los informes y artículos académicos que sustentan estas afirmaciones (UNODC, 2018; Defensor del Pueblo, 2012). Cuestión bien distinta es el modo en el que se está materializando en la práctica este triple enfoque, como veremos a continuación.

\section{PROTEGER Y ACOMPAÑAR A LAS VÍCTIMAS: UNA CUESTIÓN FEMINISTA Y DE DERECHOS}

Las normas supraestatales más importantes en la materia exigen adoptar transversalmente, en todas las actuaciones emprendidas por los poderes públicos, un enfoque de derechos con la finalidad última de proteger a las víctimas de trata de personas y combatir este tipo de delitos ${ }^{28}$. Ahora bien, cabe preguntarse qué se entiende por protección, y qué medidas concretas se ponen en práctica para garantizar la seguridad, el bienestar y el ejercicio de los derechos conculcados a quienes han sufrido trata de personas con fines de explotación sexual.

Es preciso, en primer lugar, detectar a las víctimas y conocer sus realidades, contextos y necesidades, así como las maneras en las que operan los/as tratantes, para prevenir la vulneración de derechos. A la luz de los datos, la trata de personas

${ }^{26}$ Ley Orgánica 4/2000, de 11 de enero, sobre derechos y libertades de los extranjeros en España y su integración social.

27 Ley Orgánica 19/1994, de 23 de diciembre, de protección a testigos y peritos en causas criminales.

${ }_{28}$ En concreto, podemos recordar por su relevancia el Protocolo de Palermo (artículo 2), el Convenio de Varsovia (artículo 1) o la Directiva 2011/36/UE (párrafo 7 del preámbulo y artículos 11 a 17). 
con fines de explotación sexual se manifiesta en España en la mayoría de los casos como una forma específica de violencia machista y, en particular, de un grupo heterogéneo de mujeres, a menudo migrantes, con escasos recursos económicos y redes sociales de apoyo y, por lo general, sin capacidad para enfrentarse a los grupos criminales y tratantes que se lucran con su explotación sexual.

No debemos ignorar que la existencia de víctimas y las vulneraciones de derechos sistemática que implica esta forma de trata de mujeres es conocida por las distintas instituciones del Estado, tal y como se refleja en los informes publicados por el Gobierno, las Fuerzas y Cuerpos de Seguridad, la Fiscalía General del Estado o el Defensor del Pueblo. En ese sentido, es preciso recordar que los Estados y, en este caso España, no sólo es responsable por las acciones o conductas de los agentes públicos que no respeten los derechos humanos, sino también por la omisión de las actuaciones necesarias para prevenir la comisión de unos delitos de los que se tiene constancia suficiente, así como para garantizar la protección efectiva de las víctimas.

En otras palabras, los poderes públicos ostentan las obligaciones de respetar los derechos de todas las personas bajo su jurisdicción, pero también de garantizar el ejercicio libre y pleno de esos derechos, adoptando todas las medidas necesarias (Medina \& Nash, s.f., p. 19).

Con ese fin, se ha puesto de relieve la necesidad de mejorar las medidas de prevención como forma de evitar nuevos casos de trata de personas, protegiendo así a las potenciales víctimas antes de que sean explotadas. Asimismo, los estados deben actuar con la diligencia debida a la hora de proteger a quienes ya son víctimas de este delito, con el fin de garantizar su seguridad y la no repetición del delito o re-trata, así como su recuperación integral.

El principio de diligencia debida ${ }^{29}$ genera en los estados una serie de obligaciones dirigidas a prevenir la trata, investigar y enjuiciar a los tratantes, prestar asistencia y protección a las víctimas y proporcionar vías de recurso. También incluye la identificación de las víctimas, lo que se considera clave para la investigación, el enjuiciamiento y la protección de las víctimas. En palabras de la Relatora Especial de Trata de personas, especialmente mujeres y niños (2015: párr. 9, 24 y 19):

"En la práctica, la diligencia debida se ha aplicado mayormente como una obligación reactiva, lo que ha llevado a que los Estados centren su atención en la adopción de medidas post hoc de lucha contra la trata, como la investigación y el procesamiento de la trata. En su lugar, apropiadamente constituida, la norma de diligencia debida

${ }^{29}$ El Principio 2 de los Principios y Directrices Recomendados sobre los Derechos Humanos y la Trata de Personas, elaborados por las Naciones Unidas establece que "los Estados tienen la obligación, con arreglo al derecho internacional, de actuar con la debida diligencia para prevenir la trata de personas, investigar y procesar a quienes la cometen y ayudar y proteger a las víctimas de ella”. icade. Revista cuatrimestral de las Facultades de Derecho y Ciencias Económicas y Empresariales,
$n^{\circ} 107$ mayo-agosto 2019, ISSN: 2341-0841 
permite que los Estados adopten un enfoque proactivo y a largo plazo centrado más estrechamente, por ejemplo, en el aspecto preventivo de la diligencia debida. La norma también precisa que los Estados adopten un enfoque holístico que evalúe la forma en que interactúa la diligencia debida en cada una de los diferentes ámbitos de la lucha contra la trata -como la prevención, el procesamiento y la penalización (...). Debe tenerse en cuenta la diligencia debida antes, durante y después de cada intervención contra la trata no sólo considerando cada medida por sí sola, sino también la forma en que interactúa con otras iniciativas de lucha contra la trata".

Aunque es cierto que en los últimos años se han logrado algunos avances en el plano jurídico e institucional, el desarrollo normativo y su implementación en la práctica tienen, todavía, un enfoque excesivamente penal y migratorio ${ }^{30}$, primándose la persecución del delito y el control de las fronteras, y no precisamente para garantizar los derechos de las personas migradas.

A modo de ejemplo, cabe recordar que la identificación formal de las víctimas recae en exclusiva en la Policía y la Guardia Civil y, en ocasiones depende de la voluntad de aquellas de colaborar en la investigación del delito aportando información relevante, como hemos podido comprobar en nuestro ejercicio profesional como asesoras jurídicas. Lo ha puesto de relieve el GRETA (2018, p. 38), que recomienda a España expresamente que mejore las medidas para detectar e identificar formalmente a las víctimas de una manera más efectiva e independiente de la denuncia, la colaboración con las Fuerzas y Cuerpos de Seguridad del Estado y la participación en el proceso penal.

Asimismo, la primacía del enfoque penal y migratorio y las contradicciones que entrañan respecto al enfoque de derechos queda patente si atendemos a los derechos reconocidos a las víctimas de trata de personas con fines de explotación sexual, fundamentalmente vinculados a los derechos en el proceso penal o en el contexto de las normas sobre extranjería. Por ejemplo, podemos hacer mención al periodo de restablecimiento y reflexión previsto en la llamada Ley de Extranjería, no para garantizar una recuperación y toma de decisiones informada por parte de la víctima que quizá requiera de más plazo que los noventa días previstos, sino para paralizar el expediente administrativo sancionador que se le hubieren incoado en caso de estar en una situación administrativa irregular o, en su caso, suspender la ejecución de la expulsión o devolución eventualmente acordadas, hasta que quede probada su condición de víctima.

Se afirma, por tanto, que la protección de las víctimas se ve mermada por esos enfoques, así como por el uso de estereotipos basados en el género y la raza, que entorpecen su detección e identificación (GRETA, 2018, p. 35), así como

30 De hecho, una parte importante del desarrollo normativo se encuentra en la Ley Orgánica 4/2000, de 11 de enero, sobre derechos y libertades de los extranjeros en España y su integración social, en su artículo 59 bis. 
su efectiva protección. En ese sentido es preciso recordar que la normativa internacional, europea y española que regula la lucha contra la trata de personas reconoce la necesidad de incorporar la perspectiva de género y de derechos humanos (nada se dice expresamente sobre la interseccionalidad). Sin embargo, la mención es puntual y apenas se aplica en el articulado al describir los derechos de las víctimas y las obligaciones de los Estados, de tal modo que su implementación va a depender en última instancia de la discrecionalidad de los poderes públicos.

Al mismo tiempo, se puede decir que el derecho de acceso a la Justicia se ha venido identificando en estos cuerpos normativos con la noción de "tutela judicial efectiva", que se centra en la persecución y sanción del delito y en la compensación económica a la víctima. Esto último, al menos sobre el papel, dado que buena parte de las víctimas no cobran la correspondiente indemnización (GRETA, 2018, p. 50).

La conexión de la tutela judicial efectiva con el resto de responsabilidades que poseen los Estados en materia de protección y atención es precaria, de tal manera que no se logra dar un tratamiento integral a las necesidades y experiencias de las supervivientes. En esta materia, estas normas contienen "acuerdos de mínimos". Es más, parece inferirse que se está pensando en un "modelo" muy particular de víctima, que es aquella que va a denunciar el delito, de tal manera que, aunque es cierto que en algún caso se desvincula la denuncia o la cooperación del acceso a los derechos, el resto del articulado pone el foco de atención en la judicialización.

Precisamente por ello, y antes de entrar a hacer un breve análisis sobre las mismas, conviene recordar que, sin perjuicio de la enorme utilidad del Derecho Internacional y del marco de protección de los derechos humanos, ello no obsta para que no perdamos de vista que adolece de sesgos patriarcales (y de otros tipos) que reducen sus potencialidades, al igual que sucede en el ordenamiento jurídico español. En ese sentido diversas autoras han ido planteando algunas de esas limitaciones, pero también aprendizajes y propuestas (Charlesworth \& Chinkin, 2000; Buss \& Manji, 2005; Kouvo \& Pearson, 2014). Con todo, la necesaria crítica no equivale a descartar su uso: todo lo contrario. Nos reafirmamos en la utilidad del Derecho Internacional, pero no obviamos los retos que plantea la incorporación de la perspectiva feminista al ámbito jurídico.

Veamos algunos ejemplos. En el caso del Protocolo de Palermo, no se utiliza todavía el lenguaje de la perspectiva de género y menciona a las mujeres en 4 artículos, con expresiones como "cuestiones relativas a las mujeres" (artículo 10) o "necesidades especiales de las mujeres" ${ }^{31}$. Todavía más reducida es la referencia a los derechos humanos que se mencionan en tres ocasiones, una de ellas en la cláusula de salvaguarda. En ese sentido no se puede afirmar que una y otra perspectivas hayan quedado incorporadas de manera transversal.

31 Esta última constituye un buen ejemplo del sesgo patriarcal. Son especiales porque en realidad el patrón de comparación son los hombres (MacKinnon, 1995). 
Concretamente, en materia de acceso a la Justicia, los artículos 4 a 6 regulan las cuestiones centrales ligadas a la tipificación del delito, la investigación y la sanción, con algunas referencias a las víctimas ${ }^{32}$ que son imprescindibles, pero que no siempre se plantean como responsabilidades de los estados ${ }^{33}$ y que son insuficientes hoy en día si atendemos, por ejemplo, a las deficiencias en la protección de víctimas y testigos, el limitado acceso a la información sobre los derechos que asisten a las supervivientes y las dificultades para recibir indemnizaciones (GRETA, 2018, p. 64).

En el caso del Convenio de Varsovia, se perciben notables avances, al promover expresamente la igualdad y hacer referencia a la protección de los derechos humanos de las víctimas (artículos 1, 11, 30 y 36), debiendo hacerse lo posible por integrar la perspectiva de género en el desarrollo, ejecución y evaluación de dichas medidas (artículo 17), además de recogerse expresamente el principio de no discriminación (artículo 3).

En materia de acceso a la justicia, la norma gira en torno a la tipificación (artículo 18), la investigación y actuaciones penales (artículos 27 y siguientes) ${ }^{34}$ y la sanción (artículos 23 y siguientes). Se prevé además la necesidad de garantizar la indemnización y una serie de recursos, con una regulación limitada (artículo 15) ${ }^{35}$.

No obstante lo anterior, se establece en materia de asistencia un conjunto de derechos que no pueden supeditarse a la voluntad de las víctimas de testificar y que están dirigidos al restablecimiento físico, psicológico, emocional y social de las víctimas, el cual debe proporcionarse a partir de una base consensual e informada ${ }^{36}$.

Por último, la Directiva 2011/36/UE, que ya en su objeto señala que pretende establecer las normas mínimas relativas a la definición de las infracciones penales y de las sanciones, añade que se tendrá en cuenta la perspectiva de género para

32 Entre otras, facilitar información sobre los derechos y procedimientos, utilizar una lengua que puedan comprender y expresar sus opiniones y vivencias, y que éstas sean tenidas en cuenta en las fases oportunas del proceso, proteger la privacidad y la identidad, así como la confidencialidad de las actuaciones judiciales, la seguridad física, o la posibilidad de obtener indemnizaciones.

33 Por ejemplo, el artículo 6.3 sobre la asistencia y protección señala: "Cada Estado Parte considerará la posibilidad de aplicar medidas destinadas a prever la recuperación física, psicológica y social de las víctimas de la trata de personas (...)”. O el artículo 9.2, sobre prevención: "Los Estados Parte procurarán aplicar medidas tales como actividades de investigación y campañas de información y difusión, así como iniciativas sociales y económicas, con miras a prevenir y combatir la trata de personas".

34 Es de destacar que en caso de que se inicie un proceso penal se debe garantizar que las ONGs especializadas puedan acompañar a la víctima en el curso de los procedimientos. En España, el Estatuto de la Víctima también reconoce el derecho a ser acompañadas desde el primer contacto con las autoridades por una persona de su elección (artículo 4.c).

35 Por ejemplo, el acceso a la información sobre los procedimientos en una lengua que puedan comprender o el derecho a la asistencia letrada y a justicia gratuita.

36 Entre ellos, la, asistencia médica, la formación y acceso al mercado laboral, los servicios de traducción e interpretación, o el asesoramiento para que sus derechos sean tenidos en cuenta en sede judicial (artículo 12). 
mejorar la prevención y la protección de las víctimas ${ }^{37}$. Nada se dice sobre el enfoque de derechos humanos. Siguiendo el modelo de sus antecesoras, regula la tipificación (artículo 2), la investigación y el enjuiciamiento, al que se añade que no debe depender de la denuncia de la víctima y que podrá continuar aunque la víctima se retire (artículo 9), la sanción (artículos 4 a 6), y la indemnización (artículo 17) e incorpora algunas novedades como la no imposición de penas a la víctima por delitos en su condición de tal (artículo 8). A título meramente ejemplificativo, de 25 artículos, 11 se dedican netamente a cuestiones relacionadas con los procesos penales.

En materia de atención y apoyo a las víctimas se establece como punto de partida que se adoptarán las medidas necesarias antes, durante y tras concluir el proceso penal, dentro de lo que la Directiva llama un plazo "razonable". Nos preguntamos qué significa un plazo razonable y qué ocurre con las víctimas que permanecen años fuera del sistema. A continuación, señala que se prestará siempre que haya indicios razonables de su condición de víctimas y sin que deba condicionarse a la voluntad de cooperar.

Además, apunta que las medidas garantizarán al menos la "subsistencia", teniendo en cuenta las necesidades "especiales" de las víctimas derivadas de cuestiones como el embarazo, la discapacidad o el hecho de haber sufrido ciertos tipos de violencia (artículo 11). Introduce cuestiones como el acceso al asesoramiento jurídico, la evaluación individual del riesgo, o el trato "especial" para prevenir la victimización secundaria (artículo 12). Nos preguntamos, nuevamente, si es un trato especial, ¿cuál es el ordinario? ¿cuál es el patrón de comparación?

Si bien estas normas fueron pioneras en el momento de su adopción y contribuyen tanto a la persecución y sanción como a la asistencia y protección, la realidad ha demostrado que su alcance es insuficiente.

Precisamente por lo anterior, en este trabajo partimos de una definición integral de acceso de las mujeres a la Justicia, que desborda la noción tradicional de tutela judicial efectiva y le otorga una naturaleza "pluridimensional", de acuerdo con la terminología utilizada por el Comité CEDAW en su Recomendación General número $33^{38}$, según la cual la protección de los derechos de las mujeres debe estar encaminada a garantizar su empoderamiento y autonomía y de esta manera fortalecer "el potencial de emancipación y de transformación del Derecho" (párrafo 2).

A nuestro juicio, esto entronca con el planteamiento formulado por el Feminismo Jurídico ya enunciado anteriormente, según el cual el Derecho ni es objetivo ni es neutral. Históricamente ha respondido a un modelo patriarcal de

37 El artículo 1 es el único que se refiere a esta cuestión.

38 Comité CEDAW, Recomendación General número 33 sobre el acceso de las mujeres a la justicia, UN Doc. CEDAW /C/GC/33 (2015). 
lo humano que ha impedido, entre otras cosas, que quienes no encajasen en el mismo pudiesen acceder en condiciones de igualdad a la Justicia, o simplemente acceder. Para algunas corrientes de esta disciplina, no basta con "añadir" a las mujeres o reconocer algunas de sus experiencias, debe superarse la concepción tradicional de igualdad formal y sustantiva para dar paso a una transformativa que asuma que es necesario modificar las estructuras de poder (Laporta, 2016; de las Heras, 2009). Como veremos, un acceso a la Justicia en un sentido pluridimensional supone reconocer que la tutela judicial efectiva clásica tiene profundas limitaciones derivadas, en parte, de sus raíces patriarcales.

Volviendo al planteamiento del Comitée ${ }^{39}$, éste desglosa el acceso a la Justicia en seis componentes básicos que se entrecruzan: justiciabilidad, disponibilidad, accesibilidad, buena calidad, suministro de recursos jurídicos para las víctimas y rendición de cuentas de los sistemas de justicia (párrafo 1).

La justiciabilidad exige, en esencia, que las mujeres puedan acceder sin ningún tipo de limitación a la Justicia y que se den las condiciones necesarias para que tengan la "capacidad y el poder para reclamar sus derechos" con miras a lograr su empoderamiento, y que se aplique de manera integral la perspectiva de género (párrafos 14 y 15 ).

La disponibilidad requiere que existan instituciones encargadas del acceso a la Justicia, ya sean judiciales o de otro tipo, con los recursos necesarios para desarrollar sus funciones a lo largo de todo el territorio del Estado, de tal manera que se garantice que no se van a producir discriminaciones en el acceso dependiendo del lugar de residencia de las mujeres. Estas instituciones deben contar con personal independiente y con formación especializada que se encargue del monitoreo del funcionamiento, y que preste atención a los casos de discriminación cometidos por las personas profesionales a cargo de esos servicios ${ }^{40}$.

Además, en estos dos primeros componentes se enfatiza la necesidad de cooperación con la sociedad civil y con las organizaciones especializadas para facilitar herramientas que coadyuven al acceso a la Justicia de manera sostenible y favorecer la participación de esas organizaciones en los potenciales litigios (párrafos 15 y 16$)$.

Por su parte, la accesibilidad presupone que los sistemas de Justicia deben ser físicamente accesibles, estar adaptados a las necesidades de las mujeres eliminando cualquier tipo de obstáculo (como es el caso del económico o del lingüístico),

\footnotetext{
39 Algunas de estas cuestiones se desarrollan también en la ya citada Recomendación General 35, específicamente para los supuestos de violencias contra las mujeres por razón de género.

40 Especialmente en situaciones de violencia contra las mujeres, interesa destacar que se considera imprescindible unos servicios mínimos, como son los centros de crisis, la asistencia financiera, las casas de acogida, las líneas de emergencia y los servicios médicos, psicosociales y de orientación (párrafos 14 y 16$)$.
} 
estar ubicados en lugares amables, seguros, que cuenten con dependencias de género y que se complementen con centros de atención integral (párrafos 14 y 17). En ese sentido es preciso destacar, por nuestra experiencia como acompañantes de mujeres víctimas de trata de personas con fines de explotación sexual, que en muchas ocasiones las limitaciones a la accesibilidad se derivan de sus situaciones económicas precarias y sus condicionantes familiares. De ahí que se prevea sufragar el costo del transporte hasta las instituciones judiciales y cuasi judiciales si fuera necesario, a lo que se debería sumar la creación de espacios de cuidado para sus hijos e hijas menores de edad, que faciliten que sus madres puedan hacer los trámites para ejercitar sus derechos y acudir a los lugares precisos para su recuperación integral.

Respecto a la buena calidad de los sistemas de Justicia (párrafos 14 y 18), el Comité CEDAW requiere que:

“(...) todos los componentes del sistema se ajusten a las normas internacionales de competencia, eficiencia, independencia e imparcialidad y provean, de manera oportuna, recursos apropiados y efectivos que se ejecuten y den lugar a una resolución sostenible de la controversia que tengan en cuenta las cuestiones de género para todas las mujeres. Requiere también que los Sistemas de Justicia se enmarquen en un contexto, sean dinámicos, de participación, abiertos a las medidas innovadoras prácticas, sensibles a las cuestiones de género y tengan en cuenta las crecientes demandas de Justicia que plantean las mujeres" (párrafo 14).

Todo ello en el marco de un sistema de transformación de la Justicia, que esté libre de estereotipos de género, tanto en las normas (procesales y sustantivas) como en la actividad de los órganos ${ }^{41}$ y que cuente con indicadores para medir el acceso a derechos (párrafos 14 y 18).

El quinto componente representa lo que el Comité llama el suministro de recursos, el cual sintetiza en dos elementos: protección y reparación de los daños (párrafos 14 y 19). Forman parte de este elemento los recursos judiciales y no judiciales, entre ellos los dirigidos a casos de discriminación. Estos recursos deben ser "adecuados, efectivos, atribuidos con prontitud, holísticos y proporcionales a la gravedad del daño sufrido" e incluyen la restitución, la indemnización y la rehabilitación, de las que hablaremos más adelante ${ }^{42}$, así como la necesidad de que existan fondos específicos para aquellos casos en los que los responsables no paguen las indemnizaciones y compensaciones.

41 El Comité dedica los artículos 26 y siguientes a desgranar los graves efectos que tienen los estereotipos de género en el ámbito judicial y propone medidas para reducir su uso. Sobre esta materia, véase también Cook \& Cusack (2010).

42 La Recomendación General 35 añade la satisfacción y las garantías de no repetición. 
Por último, la indispensable y a menudo olvidada rendición de cuentas de los sistemas de Justicia, sirve para determinar en qué medida se cumple con los cinco primeros componentes respecto de las instancias judiciales y administrativas, incluyendo la supervisión de las acciones de las personas profesionales que intervienen, determinando, en su caso, la correspondiente responsabilidad en caso de incumplimiento y las medidas disciplinarias. A ello se añade la recomendación de crear organismos que faciliten recoger las "quejas, peticiones y sugerencias", y de elaborar estudios desde la perspectiva de género que permitan desentrañar los obstáculos y las buenas prácticas para que sean tenidos en cuenta en el diseño y mejora de las políticas públicas (párrafos 14 y 20).

Nos interesa ahora detenernos en una de las "piezas" que componen este sistema, específicamente las reparaciones. Como es bien sabido, el impacto diferenciado que tienen las violaciones a los derechos humanos en hombres y mujeres requiere que las reparaciones se diseñen, implementen y evalúen atendiendo a este extremo y, por lo tanto, se aborden desde la perspectiva de género. El término "reparaciones" es todavía poco habitual en España. Si bien es cierto que algunas de las normas más relevantes de protección de los derechos humanos en el sistema universal se refieren a la reparación ${ }^{43}$, su alcance tal y como lo conocemos hoy en día se ha ido concretando mediante la actuación de los órganos encargados de su supervisión, incluidos los mandatos de los procedimientos especializados $^{44}$, tanto mediante las Recomendaciones Generales e informes, como a través de su jurisprudencia ${ }^{45}$. Dicho esto, ha sido en el sistema interamericano de protección de los derechos humanos donde ha tenido un recorrido más completo ${ }^{46}$.

43 A modo de ejemplo: Pacto Internacional de Derechos Civiles y Políticos, Resolución 2200 A (XXI), de 16 de diciembre de 1966; Convención Internacional sobre la Eliminación de todas las Formas de Discriminación Racial, Resolución 2106 A (XX), de 21 de diciembre de 1965; Convención contra la Tortura y Otros Tratos o Penas Crueles, Inhumanos o Degradantes, Resolución 39/46, de 10 de diciembre de 1984; Convención internacional sobre la protección de los derechos de todos los trabajadores migratorios y de sus familiares, Resolución 45/158, de 18 de diciembre de 1990.

${ }^{44}$ Como es el caso de los de la Relatora Especial sobre la trata de personas, especialmente mujeres y niños.

45 En el caso de la Convención CEDAW no se menciona como tal la reparación pero algunas de sus Recomendaciones Generales como la citada número 35 han ido reconociendo esta figura y dotándola de contenido. Aunque hasta la fecha no contamos con jurisprudencia del Comité CEDAW sobre trata de personas (todas las comunicaciones han sido declaradas inadmisibles), hay otras decisiones sobre violencia contra las mujeres por razón de género que nos acercan a las reparaciones en esta materia. Para el caso español: Comité CEDAW, Asunto Ángela González Carreño, Comunicación núm. 47/2012, de 16 de julio de 2014, UN Doc. CEDAW/C/58/D/47/2012. Además, el Comité ha establecido un grupo de trabajo sobre trata de mujeres y niñas en el contexto de la migración global con el objetivo de elaborar en el futuro un borrador de Recomendación General sobre esta materia.

${ }^{46}$ Respecto a casos de violencia contra las mujeres, podemos destacar en materia de reparaciones: Corte Interamericana de Derechos Humanos, Caso González y otras ("Campo Algodonero") vs. México. Excepción Preliminar, Fondo, Reparaciones y Costas. Sentencia de 16 de noviembre de 2009; Caso 
Al mismo tiempo, su uso ha estado muy vinculado a contextos de violaciones masivas de derechos humanos, y así ha quedado recogido en normas internacionales como los Principios y directrices básicos sobre el derecho de las víctimas de violaciones manifiestas de las normas internacionales de derechos humanos y de violaciones graves del Derecho internacional humanitario a interponer recursos y obtener reparaciones ${ }^{47}$, el Conjunto de principios actualizado para la protección y la promoción de los derechos humanos mediante la lucha contra la impunidad ${ }^{48}$, o la Declaración de Nairobi sobre el derecho de las mujeres y las niñas a interponer recursos y obtener reparaciones $^{49}$. Existe, además, una amplia literatura científica sobre las reparaciones en estos contextos (De Greiff, 2006), así como particularmente sobre su estudio desde el enfoque de género (Rubio-Marín, 2009) ${ }^{50}$, cuestiones éstas sobre las que no pretendemos profundizar en este artículo.

Grosso modo, se distingue entre medidas más clásicas, como la restitución (devolver a la víctima a la situación anterior a la violación de sus derechos) y la indemnización; y otras como la recuperación ${ }^{51}$ (atención médica, psicológica, social y jurídica), la satisfacción y las garantías de no repetición ${ }^{52}$, éstas últimas dirigidas fundamentalmente a la prevención de violaciones futuras de los derechos humanos ${ }^{53}$.

Fernández Ortega y otros vs. México. Excepción Preliminar, Fondo, Reparaciones y Costas. Sentencia de 30 de agosto de 2010; Caso Rosendo Cantú y otra vs. México. Excepción Preliminar, Fondo, Reparaciones y Costas. Sentencia de 31 de agosto de 2010; Caso Veliz Franco y otros vs. Guatemala. Excepciones Preliminares, Fondo, Reparaciones y Costas. Sentencia de 19 de mayo de 2014; Caso Espinoza Gonzáles vs. Perú. Excepciones Preliminares, Fondo, Reparaciones y Costas. Sentencia de 20 de noviembre de 2014; Caso Velásquez Paiz y otros vs. Guatemala. Excepciones Preliminares, Fondo, Reparaciones y Costas. Sentencia de 19 de noviembre de 2015; Corte IDH. Caso Favela Nova Brasília vs. Brasil. Excepciones Preliminares, Fondo, Reparaciones y Costas. Sentencia de 16 de febrero de 2017; Caso López Soto y otros vs. Venezuela. Fondo, Reparaciones y Costas. Sentencia de 26 de septiembre de 2018; Caso Mujeres víctimas de tortura sexual en Atenco vs. México. Excepción Preliminar, Fondo, Reparaciones y Costas. Sentencia de 28 de noviembre de 2018.

47 Asamblea General de Naciones Unidas, Resolución 60/147 (2005).

48 Comisión de Derechos Humanos, Un. Doc. E/CN.4/2005/102/Add.1 (2005).

49 A diferencia de las dos anteriores, ésta no es esta una norma de soft law. Se emite en el marco de una reunión celebrada en Nairobi en 2007, por defensoras y activistas de los derechos de las mujeres, asî como por sobrevivientes de violencia sexual en situaciones de conflicto armado.

50 Se mencionan algunas obras clásicas a título meramente ejemplificativo, pero desde entonces son numerosas las publicaciones destinadas al estudio de esta materia.

${ }^{51}$ El término utilizado en la normativa internacional es rehabilitación. Sin embargo, consideramos más apropiado el de recuperación, expresión utilizada también por la Relatora (2015, párrafo 10), por tener una connotación menos asistencialista y menos estereotipada sobre las supervivientes.

${ }^{52}$ Existe una discusión doctrinal sobre si las garantías de no repetición deben ser consideradas como una forma de reparación o como medidas diferentes. Véase Calvet \& Pons (2018).

${ }_{53}$ Una explicación detallada de cada una de ellas se puede encontrar en la citada Resolución 60/147 (2005). 
Interesa detenerse brevemente en la Declaración de Nairobi por su relación con el tema objeto de estudio en este artículo. Parte de la necesidad de adoptar un enfoque transformador, de tal manera que las reparaciones, por una parte, deben estar dirigidas a las supervivientes, pero al mismo tiempo deben impeler medidas que se dirijan a eliminar las estructuras de discriminación y desigualdad que están en la base de la vulneración de los derechos de las mujeres.

Ésta es una de las claves de las reparaciones cuando hablamos de violencias contra las mujeres por razón de género, y por ende también de la trata con fines de explotación sexual. En esta Declaración se señalan cuestiones como que las reparaciones, individuales y colectivas, deben estar adaptadas a las "necesidades, intereses y prioridades" de las mujeres y que deben ser ellas quienes las determinen; que deben promover su (mayor) empoderamiento y autonomía, así como su participación en la toma de decisiones, debiendo asegurarse especialmente en el caso del diseño, la implementación y evaluación de las propias reparaciones, teniendo siempre presente las barreras a las que se enfrentan por el hecho de ser mujeres. Se apela, de ese modo, a la construcción de una "memoria y una historia compartidas".

En sentido similar, la Recomendación General 35 ha venido a reiterar esta idea. Se establece que las reparaciones, que deben poder ser tanto administrativas como judiciales, individuales y colectivas, deben estar centradas en las supervivientes, contar con ellas y ser transformativas en el sentido de abordar los patrones de discriminación que están en la raíz de las violencias (párrafo 33).

En el caso particular de la trata de mujeres con fines de explotación sexual, su regulación en las tres normas internacionales y regionales mencionadas a lo largo de este artículo ha sido muy desigual. No se utiliza ese lenguaje, pero se reconocen algunas de esas reparaciones, habiéndose priorizado las que llamamos de indemnización, restitución y rehabilitación ${ }^{54}$.

Sí lo hace claramente la Relatora, quien parte de la obligación de los estados, en virtud del Derecho Internacional, de garantizar el derecho a un recurso efectivo a las víctimas como parte del principio de debida diligencia. Y señala que esa reparación entraña la restitución, la rehabilitación, la indemnización, la satisfacción y las garantías de no repetición y que "deben tener un "potencial transformativo", lo que significa que no deberían limitarse a devolver a las personas al contexto anterior a la trata, sino que deben "subvertir, en vez de reforzar, los patrones preexistentes" que puede ser causas de las violaciones" (Relatora, 2015, párrafo 34). Y advierte que una "identificación rápida y exacta de las víctimas de la trata de

54 Sí lo hacen los Principios y Directrices recomendados sobre los derechos humanos y la trata de personas en su Directriz novena, sobre el acceso a los recursos, en la que menciona la indemnización como una forma de reparación. No menciona otras, pero tampoco las descarta. 
personas, además de ser parte de la obligación de prevención del Estado, también es una condición previa esencial para realizar el derecho a una reparación" (Relatora, 2015, párrafo 36).

Esta concepción de reparación integral, con mayor o menor alcance, ha comenzado a reconocerse como una obligación de los estados en legislaciones estatales sobre violencia contra las mujeres por razón de género ${ }^{55}$. Destaca el caso de Ecuador, que cuenta con una ley que incorpora los cinco tipos de reparaciones y prevé mecanismos judiciales y administrativos dirigidos a restablecer el "proyecto de vida de las víctimas", expresión ésta que contrasta, por ejemplo, con la de subsistencia manejada en la Directiva 2011/36/UE.

No es el caso de la legislación estata ${ }^{56}$, aunque sí se ha empezado a reconocer en la autonómica, sobresaliendo el caso de Cataluña ${ }^{57}$ y muy especialmente el de Navarra ${ }^{58}$ donde se recogen principios como el respeto y no revictimización garantizando medidas que se dirijan a lograr la autonomía y libertad de las supervivientes y que tenga en cuenta sus necesidades (artículo 6), contando incluso con un título destinado a la reparación (artículo 70 y siguientes).

En fin, nada impediría, desde un punto de vista puramente legal, que se optase en el ordenamiento jurídico español por una regulación como la mencionada. Y es que los ejemplos señalados más arriba no son más que concreciones de las perspectivas de género y derechos, las cuales, como decíamos, se erigen como principios básicos de actuación de los poderes públicos en el Protocolo de Palermo, el Convenio de Varsovia y la Directiva 2011/36/UE.

\section{CONCLUSIONES}

Atendiendo a los datos e informes analizados, es posible afirmar que la trata de personas con fines de explotación sexual en España representa un delito complejo. En este artículo se ha querido poner de manifiesto que esa complejidad desborda las cuestiones puramente penales relacionadas con las dificultades relativas a la

55 México: Ley general de acceso de las mujeres a una vida libre de violencia (2007); Colombia: Ley por la cual se dictan normas de sensibilización, prevención y sanción de formas de violencia y discriminación contra las mujeres (2008); El Salvador: Ley especial integral para una vida libre de violencia para las mujeres (2011); Paraguay: Ley de protección integral a las mujeres, contra toda forma de violencia (2016); Uruguay: Ley que dicta normas contra la violencia hacia las mujeres basada en género (2017); Ecuador: Ley orgánica integral para la prevención y erradicación de la violencia de género contra las mujeres (2018).

${ }^{56}$ Es cierto que data del año 2004, cuando todavía no existía la normativa internacional que lo ha desarrollado. La Ley 4/2015, de 27 de abril, del Estatuto de la víctima del delito sí se refiere a reparaciones pero de manera más limitada que las leyes latinoamericanas y con un alcance desde la perspectiva de género mucho menor.

${ }^{57}$ Ley 5/2008, de 24 de abril, del derecho de las mujeres a erradicar la violencia machista.

${ }^{58}$ Ley foral 14/2015, de 10 de abril, para actuar contra la violencia hacia las mujeres. 
investigación, persecución y sanción del delito. No podemos obviar que son miles las personas afectadas, que una ínfima parte son consideradas legalmente como víctimas y que no todas logran una sentencia condenatoria contra los/as tratantes, con las consecuencias que ello supone actualmente en términos de reparaciones económicas.

Conlleva gravísimas vulneraciones de los derechos humanos de personas que se ven privadas de libertad, en situaciones de extrema vulnerabilidad y sometidas a múltiples violencias y discriminaciones que, sin duda, suponen una violación de derechos tan básicos como la libertad sexual, la integridad y el bienestar físico, psicológico, emocional y social e, incluso, un riesgo para su propia vida. Esta situación se puede prolongar durante años y las condiciones de precariedad y vulnerabilidad continúan incluso si logran salir de las redes o las situaciones de explotación.

Por lo anterior, es imprescindible una actuación integral y coordinada por parte de los poderes públicos, quienes deben escuchar a las supervivientes y facilitar su participación en los procesos de diseño, implementación y evaluación de las normas y políticas públicas. Sus experiencias, vivencias y necesidades deberían estar en el centro.

Lo primero exige, como punto de partida, una ley integral que abandone el modelo actual, disgregador, de mínimos, que aborda tan sólo algunas de las vertientes de la trata de personas y lo hace como si de compartimentos estancos se tratara. Una ley que no se limite simplemente a recoger lo que ahora está disperso, sino que incorpore las obligaciones que el Estado tiene en materia de trata de personas, teniendo en cuenta la interpretación que de ellas han dado los organismos internacionales y las buenas prácticas en otros países, con una aplicación rigurosa del enfoque de derechos humanos, feminista e interseccional. El Derecho puede y debe ser transformador.

Lo segundo requiere, en línea con lo anterior, que todas las actuaciones, normativas o de cualquier otro tipo que se lleven a cabo tengan como fin último aspirar al empoderamiento, la autonomía y la garantía de los derechos de las supervivientes. De todas, porque han sido víctimas, pero continúan siendo personas, cada una con sus experiencias, necesidades y fortalezas.

Es una exigencia de Justicia, es una cuestión de derechos. 


\section{BIBLIOGRAFÍA}

Bartlett, K. (1990). Feminist Legal Methods. Harvard Law Review, 103 (4), 829 888.

Bartlett, K. \& Kennedy, R. (eds.)(1991). Feminist Legal Theory: Readings in Law and Gender. Boulder: Westview Press.

Barnett, H. (1998). Introduction to Feminist Jurisprudence. London: Cavendish Publishing Limited.

Buss, D. \& Manji, A. (ed.) (2005). International Law. Modern Feminist Approaches. Oxford, UK: Hart Publishing Ltd.

Calvet, E. \& Pons, X. (2018). El fortalecimiento de la independencia judicial en los procesos de justicia transicional como garantía de no repetición. Revista Española de Derecho Internacional, 70 (2), 71-99. Disponible en:

http://dx.doi.org/10.17103/redi.70.2.2018.1.03

Charlesworth, C. \& Chinkin, C. (2000). The boundaries of international law. A feminist analyses. Manchester, UK: Manchester University Press.

Chuang, J. (1998). Redirecting the debate over Trafficking in Women: Definitions, Paradigms and Contexts. Harvard Human Rights Journal, 11, 65-107.

Chuang, J. (2013). Article 6. En Freeman, M.A., Chinkin, C. \& Rudolf, B. (eds.), The UN Convention on the Elimination of all Forms of Discrimination against women. A Commentary (pp. 169-196). Oxford, UK: Oxford University Press.

Cook, R. \& Cusack, S. (2010). Gender stereotyping. Transnational Legal Perspectives. Philadelphia, USA: University of Pennsylvania Press.

Cortés, J., Becerra, G., López, L. \& Quintero, L. (2011). ¿Cuál es el problema de la trata de personas? Revisión de las posturas teóricas desde las que se aborda la trata. Revista Nova et Vetera, 20 (64), 105-120.

De Greiff, P. (2006). The handbook of reparations. Oxford, UK: Oxford University Press.

De las Heras, S. (2009). Una aproximación a las teorías feministas. Universitas. Revista de Filosofía, Derecho y Política, 9, 45-82. Disponible en: http://universitas.idhbc.es/n09/09-05.pdf

Facio, Alda \& Fries, Lorena (eds.). (1999). Género y Derecho. Santiago de Chile: LOM Ediciones, La Morada.

Kouvo, S. (Ed.). (2014). Feminist Perspectives on Contemporary International Law. Between Resistance and compliance. Oxford, UK: Hart Publishing Ltd.

Laporta, E. (2016). Desde la Convención sobre la Eliminación de todas las formas de discriminación de la mujer a la igualdad transformativa en España. En La Barbera, M. \& Cruells, M (eds.), Igualdad de género y no discriminación en España: evolución, problemas y perspectivas (pp. 59-82). Madrid: Centro de Estudios Políticos y Constitucionales. 
MacKinnon, C. (1982). Feminism, Marxism, Method, and the State: An Agenda for Theory. Signs: Journal of Women in Culture and Society, 7, 515-544.

MacKinnon, C. (1995). Hacia una teoría feminista del Estado. Madrid: Ediciones Cátedra.

MacKinnon, C. (2013). Intersectionality as a method. A note. Signs: Journal of Women in Culture and Society, 38 (4), 1019-1030.

Medina, C. \& Nash, C. (s.f.). Manual de Derecho Internacional de los Derechos Humanos. Disponible en: https://www.fundacionhenrydunant.org/images/ stories/biblioteca/derechos humanos/MEDINA C. y NASH C. 2003.Manual de Derecho Internacional de los DDHH.pdf

Rubio-Marín, R. (Ed.). (2009). The gender of reparations. Unsettling sexual hierarchies while redressing human rights violations. New York, USA: Cambridge University Press.

\section{INFORMES}

CGPJ (2017). Estudio de investigación en materia de trata de seres humanos, que se presenta a la Comisión de Igualdad del Consejo General del Poder Judicial. Disponible en: http://www.poderjudicial.es/stfls/CGPJ/OBSERVATORIO\%20 DE\%20VIOLENCIA \%20DOM\%C3\%89STICA/ESTUDIOS/FICHE$\mathrm{RO} / 20170227 \% 20$ Estudio\%20de\%20investigaci\%C3\%B3n\%20en\%20materia\%20de\%20trata\%20de\%20seres\%20humanos.pdf

CITCO (2018). Trata de seres humanos en España. Balance estadístico 2013-17. Disponible en: http:/www.interior.gob.es/documents/10180/6744515/Balan$\mathrm{ce}+2013-2017+\mathrm{de}+$ Trata+de+Seres+Humanos+en+Espa\%C3\%B1a.pdf/1fa3 bec6-4f1d-4d65-a6a8-5a6ac84c6b81

Defensor del Pueblo (2012). La trata de seres humanos en España: víctimas invisibles. Disponible en: https://www.defensordelpueblo.es/wp-content/uploads/ 2015/05/2012-09-Trata-de-seres-humanos-en-Espa\%C3\%B1a-v\%C3\%ADctimas-invisibles-ESP.pdf

Fiscalía (2018). Diligencias de seguimiento del delito de trata de seres humanos. Año 2017. Disponible en: https://www.fiscal.es/fiscal/PA_WebApp_SGNTJ_NFIS/ descarga/DILIGENCIAS\%20DE\%20SEGUIMIENTO\%202017-1 ?idFile=Offf76e9-aac9-45ec-bb27-ea1c692dcd33

Relatora Especial sobre la trata de personas, especialmente mujeres y niños (2015). Informe. Disponible en: https://documents-dds-ny.un.org/doc/UNDOC/GEN/ N15/241/40/PDF/N1524140.pdf?OpenElement

Relatora Especial sobre la violencia contra la mujer, con inclusión de sus causas y consecuencias, sobre la trata de mujeres, la migración de mujeres y la violencia 
contra la mujer (2000). Informe sobre la integración de los derechos humanos de la mujer y la perspectiva de género. Disponible en: https://documents-dds-ny. un.org/doc/UNDOC/GEN/G00/113/34/PDF/G0011334.pdf?OpenElement

UNODC (2018). Global Report on Trafficking in Persons 2018. Disponible en: https://www.unodc.org/unodc/data-and-analysis/glotip.html

UNODC (2010). The Globalization of Crime. A Transnational Organized Crime Threat Assessment. Disponible en: http://www.unodc.org/res/cld/bibliography/ the-globalization-of-crime-a-transnational-organized-crime-threat-assessment_html/TOCTA_Report_2010_low_res.pdf 